\title{
Geometrical and friction properties of perennial grasses and their weeds in view of an electro-separation method
}

\author{
Stepan J. Kovalyshyn ${ }^{*}$, Viktor O. Dadak1, Vitalij V. Sokolyk ${ }^{1}$, Stanisław Grundas ${ }^{2}$, \\ Mateusz Stasiak ${ }^{2}$, and Jerzy Tys ${ }^{2}$ \\ ${ }^{1}$ Lviv National Agriculture University, 80381 Lviv-Dublyany, Ukraine \\ ${ }^{2}$ Institute of Agrophysics, Polish Academy of Sciences, Doświadczalna 4, 20-290 Lublin, Poland
}

Received October 12, 2014; accepted December 2, 2014

\begin{abstract}
A b s t r a c t. Many seed mixtures of herbs are difficult to separate. This is confirmed by studies determining the basic geometrical and friction properties of the seeds of perennial grasses and seeds of their weeds. The results show that in most cases the value of their geometrical parameters (length, thickness, and width) and friction properties (friction coefficients for different external surfaces of internal friction coefficients) are substantially similar and differ slightly among each other. This is the evidence that these properties are impractical to use in the process of separation as signs of divisibility. In the paper, a method for electro-separation of seed mixtures of herbs based on the use of complex physical, mechanical properties and electrical components in the separation are presented. The electric field that acts as an additional working body allows considering the surface conditions and biological status of seed mixtures of particles and significantly expands the functionality of the separators. Confirmation of the effectiveness of the proposed method for separation can be seen in the example of purification of red clover and sorrel seeds. By imposition of an electric field on an inclined moving separating plane, we can completely separate weed seeds from the main crop. The results confirm the effectiveness of the electro-separating method.

$\mathrm{K}$ e y w o r d s: seeds of grasses and weeds, physical properties, separation method
\end{abstract}

\section{INTRODUCTION}

The process of separation of seeds of perennial grass species from seeds of their weeds requires knowledge of their physical properties. In practice, separation processes are reduced to multiple cleaning (Zaika, 2006). The main traits that determine the effectiveness of separation of seeds is their differentiation in terms of shape and surface (Shevchuk, 2011). Among the numerous factors that affect

*Corresponding author e-mail: kovalyshyn@mail.ru the flow of a granular material against structural surfaces, the most important include the kind of surface, its roughness, slip distance, slip velocity, surface properties of the granular material, its moisture, spatial orientation of the grains relative to the slip direction, and the humidity and temperature of the environment (Horabik and Molenda, 1988, 1989; Molenda et al., 1995, 2000).

Until now, no effective machines have been available that would be able to separate undesirable seeds from a mixture with satisfactory accuracy conforming to the current standards of species purity (Samokish, 2001). Therefore, it is necessary to conduct a detailed study of those physical properties of seeds that will facilitate development of effective designs of machines for cleaning and separating the base material from contaminants and seeds of undesirable species. The problem of the physical properties of seeds has been addressed in a number of publications (Anonymous, 2002; Balasubramianian et al., 2012; Ch'ng et al., 2013; Kovalyshyn et al., 2013; Zare et al., 2013). Zaika (2006) discusses issues related to the entire complex of physical properties of plants. For acquisition of statistical data, measurements of the coefficients friction were conducted using an apparatus with a sloping and adjustable conveyor plane. However, the apparatus does not ensure sufficient measurement accuracy and does not meet the requirements for the process of separation of seeds of plant species from the families Fabaceae and Poaceae. To facilitate such measurements, a device was proposed in which the sloping surface of the conveyor moves with an adjustable angle of inclination (Ribaruk, 1998).

(C) 2015 Institute of Agrophysics, Polish Academy of Sciences 
For precise measurement of the angle of friction and of the coefficient of external friction, the Żeligowski apparatus was applied (Shevchuk, 2011). The operation of the apparatus consists in sliding a sample of seeds of a plant species over a sloping surface (Tomiuk, 2006). However, this apparatus is not perfect either, as it does not ensure separation of seeds with satisfactory accuracy. The experiment requires determination of the angle of external friction at a large number of operations, which makes the process of calculation difficult. The given conditions indicate a need for improving the methodology and extension of the scope of the study with determination of friction coefficients of samples of seeds of various plant species.

The aim of this paper was to show a possibility of using methods for electro-separation of seeds of perennial grasses from their weeds on the basis of geometrical and mechanical properties of seeds. The Jenike apparatus in conformance with the method recommended by Eurocode 1 was used.

\section{MATERIALS AND METHODS}

The experimental material consisted of three groups of perennial grasses. Group one-seeds of plants from the family Fabaceae and hard-to-remove seeds of their weeds, group two - seeds of plants from the family Poaceae and hardto-remove seeds of their weeds, and group three - seeds of plants from the family Poaceae and hard-to-remove seeds of weeds from the family Asteraceae. The experiments also involved seeds of weeds that are hard to remove from seeds of each of the three groups of perennial plants. The group of perennial plants from the family Fabaceae included white clover, red clover (Trifolium prentense), and its hybrid Swedish clover and the seeds of their most frequent weeds, ie white melilot, sorrel, and English plantain. The group of perennial plants from the family Poaceae included tall meadow oat, English ryegrass, orchard grass, meadow fescue, and smooth brome and the seeds of their weeds, ie couch grass, and Suffolk lungwort. The third group included seeds of a Poaceae species - timothy grass and seeds of its weeds from the family Asteraceae ie scented mayweed (Table 1).

The electro-separation method used relies on the difference between the physical, mechanical, and electrical properties of the components of the seed mixture.

Coefficients of external friction and of the angle of internal friction of seeds of the examined groups were determined on glass, steel, aluminium, and belted surfaces. The determinations were made with the use of the Jenike apparatus (Fig. 1) in conformance with the method recommended by Eurocode 1 (2006).

The principle of operation of the Jenike apparatus consists in recording the force of the movement of two rings relative to each other in the horizontal plane. A consolidated sample is placed in the chamber composed of two rings.
The Eurocode 1 standard recommends that the strength parameters of a granular material: the angle of internal friction $\varphi$, effective angle of internal fraction $\delta$ and cohesion $c$ should be determined in the Jenike apparatus according to a simplified procedure including preliminary consolidation and shearing of the sample (Fig. 2). The strength parameters of a granular material should be determined on the basis of two separate tests performed in accordance with the procedure: one sample consolidated and sheared at normal stress $\sigma_{r}$ and a second sample, consolidated at reference pressure $\sigma_{r}$ and then sheared at normal stress $1 / 2 \sigma_{r}$. The diameter (D) of the shear chamber should be at least 40-fold larger than the maximum dimension of a single kernel of the sample studied, and height $\mathrm{H}$ should be within the range of $0.3-0.4 \mathrm{D}$.

In the course of the experiments, the main dimensions of the seeds (length, thickness, and width) were determined. Measurements of the geometric parameters of the seeds were conducted at $20^{\circ} \mathrm{C}$ and humidity less than $80 \%$ by a bilateral calliper produced according to ISO 9002. Indication of measurement results was transferred into LCD digital display, which facilitated the process. The electronic unit of the calliper enabled us to output the data into a computer or ICS controller workstation RS232 (COM - Port). The geometric features were determined for 100 seeds from each sample studied. The determinations of the coefficient of external friction were conducted in the Laboratory of Mechanics of Granular Materials, Institute of Agrophysics PAS in Lublin. Seeds of particular plant species differ in terms of frictional properties. One of the more important causes is the difference in surface roughness and texture of the seeds.

In the case of materials of plant origin, moisture is one of the primary causes of variation of the friction coefficient. The coefficient of friction usually increases with an increase in seed moisture, especially above $13 \%$. The relation between seed moisture and relative air humidity has a significant effect on the value of the coefficient of friction. Seeds deform more easily on areas of surface irregularity. An increase in seed moisture also causes a decrease in the height of irregularities on the seed surface. A combination of those effects results in an increase in the value of force required to break the frictional contact. With a moisture increase above $20 \%$, free space appears between the surfaces, weakening the strength of the contact, and the value of the coefficient of friction begins to decrease. Table 1 presents the results of seed moisture measurement conducted in halogen moisture apparatus Mettler Toledo type HG 63 made in USA and friction parameters.

The standard Eurocode 1 recommends that the coefficient of external friction should be determined in the Jenike apparatus, replacing the lower part of the measurement chamber with the structural material for which the coefficient of friction is to be determined. The ratio of sample height to its diameter should be within the range of 0.15-0.2. 
T a b l e 1. Results of measurements of the coefficient of friction for seeds of perennial plant and their weeds

\begin{tabular}{|c|c|c|c|c|c|c|}
\hline \multirow{2}{*}{ Groups and species } & \multirow{2}{*}{$\begin{array}{l}\text { Moisture } \\
\text { (\%) }\end{array}$} & \multicolumn{4}{|c|}{ Coefficient of external friction /angle of friction } & \multirow{2}{*}{$\begin{array}{c}\text { Angle of } \\
\text { internal friction } \\
\varphi\end{array}$} \\
\hline & & glass & steel & aluminium & belt & \\
\hline \multicolumn{7}{|c|}{ Group I. Seeds of plant species from the family Fabaceae } \\
\hline $\begin{array}{l}\text { White clover } \\
\text { (Trifolium repens) }\end{array}$ & 6.05 & $\begin{array}{c}0.278 / \\
15 \pm 2 \%\end{array}$ & $\begin{array}{c}0.213 / \\
12 \pm 1 \%\end{array}$ & $0.242 / 13 \pm 2.3 \%$ & $0.491 / 28 \pm 3 \%$ & $29.133 \pm 4 \%$ \\
\hline $\begin{array}{l}\text { Red clover } \\
\text { (Triforium pratense) }\end{array}$ & 7.02 & $0.258 / 14 \pm 3 \%$ & $0.217 / 12 \pm 1.8 \%$ & $0.246 / 13 \pm 2.1 \%$ & $0.471 / 27 \pm 2.5 \%$ & $28.332 \pm 3.4 \%$ \\
\hline $\begin{array}{l}\text { Swedish clover } \\
\text { (Triforium hibridum) }\end{array}$ & 7.41 & $0.223 / 12 \pm 1.5 \%$ & $0.215 / 12 \pm 2.2 \%$ & $0.234 / 13 \pm 3.5 \%$ & $0.493 / 28 \pm 3.1 \%$ & $25.840 \pm 1.9 \%$ \\
\hline \multicolumn{7}{|c|}{ Hard to remove seeds of weeds from the family Fabaceae } \\
\hline $\begin{array}{l}\text { English ryegrass } \\
\text { (Plantago lanceolata L.) }\end{array}$ & 6.15 & $0.231 / 13 \pm 0.7 \%$ & $0.219 / 12 \pm 1.3 \%$ & $0.242 / 13 \pm 2.7 \%$ & $0.412 / 23 \pm 1.8 \%$ & $27.235 \pm 2.2 \%$ \\
\hline $\begin{array}{l}\text { Sorrel } \\
\text { (Rumex confertus) }\end{array}$ & 7.26 & $0.242 / 13 \pm 1.3 \%$ & $0.232 / 13 \pm 1.6 \%$ & $0.237 / 13 \pm 3.1 \%$ & $0.436 / 24 \pm 2.4 \%$ & $28.332 \pm 1.5 \%$ \\
\hline $\begin{array}{l}\text { White melilot } \\
\text { (Melilotus albus) }\end{array}$ & 6.24 & $0.271 / 15 \pm 2.2 \%$ & $0.276 / 15 \pm 2.6 \%$ & $0.265 / 14 \pm 3.6 \%$ & $0.424 / 24 \pm 2.9 \%$ & $27.652 \pm 3 \%$ \\
\hline \multicolumn{7}{|c|}{ Group II. Seeds of plant species from the family Poaceae } \\
\hline $\begin{array}{l}\text { English ryegrass } \\
\text { (Lolium perene L.) }\end{array}$ & 9.95 & $0.213 / 12 \pm 2.8 \%$ & $0.186 / 10 \pm 2 \%$ & $0.260 / 14 \pm 2.3 \%$ & $0.421 / 23 \pm 1.6 \%$ & $30.642 \pm 2.6 \%$ \\
\hline $\begin{array}{l}\text { Tall meadow oat } \\
\text { (Arhenahterum elatius L.) }\end{array}$ & 7.84 & $0.210 / 11 \pm 2.1 \%$ & $0.190 / 10 \pm 2.3 \%$ & $0.282 / 15 \pm 3.5 \%$ & $0.438 / 25 \pm 2.8 \%$ & $29.968 \pm 3.1 \%$ \\
\hline $\begin{array}{l}\text { Orchard grass } \\
\text { (Dactylis glomerate L.) }\end{array}$ & 8.51 & $0.236 / 13 \pm 3 \%$ & $0.236 / 13 \pm 1.9 \%$ & $0.254 / 14 \pm 2.6 \%$ & $0.542 / 31 \pm 2.2 \%$ & $29.832 \pm 2.9 \%$ \\
\hline $\begin{array}{l}\text { Meadow fescue } \\
\text { (Festuca pratensis Huds) }\end{array}$ & 8.40 & $0.263 / 14 \pm 0.5 \%$ & $0.240 / 13 \pm 2.6 \%$ & $0.297 / 16 \pm 1.7 \%$ & $0.436 / 23 \pm 1.3 \%$ & $37.231 \pm 1.9 \%$ \\
\hline $\begin{array}{l}\text { Smooth brome } \\
\text { (Bromus inermis Leyss) }\end{array}$ & 8.27 & $0.170 / 9 \pm 3.3 \%$ & $0.115 / 6 \pm 3.5 \%$ & $0.223 / 9 \pm 3 \%$ & $0.425 / 23 \pm 2.4 \%$ & $38.982 \pm 2.9 \%$ \\
\hline \multicolumn{7}{|c|}{ Hard to remove seeds of weeds from the family Poaceae } \\
\hline $\begin{array}{l}\text { Suffolk lungwort } \\
\text { (Pulmonaria obscura L.) }\end{array}$ & 8.02 & $0.253 / 14 \pm 1.7 \%$ & $0.241 / 14 \pm 1.9 \%$ & $0.246 / 14 \pm 2.2 \%$ & $0.435 / 24 \pm 1.2 \%$ & $33.345 \pm 1.5 \%$ \\
\hline $\begin{array}{l}\text { Couch grass } \\
\text { (Elytrigia repens L.) }\end{array}$ & 8.15 & $0.320 / 18 \pm 4.3 \%$ & $0.310 / 17 \pm 2.9 \%$ & $0.350 / 19 \pm 3.3 \%$ & $0.442 / 25 \pm 3.8 \%$ & $35.935 \pm 3.5 \%$ \\
\hline \multicolumn{7}{|c|}{ Group III. Seeds of plant species from the family Poaceae } \\
\hline $\begin{array}{l}\text { Timothy grass } \\
\text { (Phleum pretense L.) }\end{array}$ & 8.50 & $0.223 / 12 \pm 5 \%$ & $0.213 / 12 \pm 2.8 \%$ & $0.230 / 13 \pm 2.1 \%$ & $0.438 / 24 \pm 3.8 \%$ & $31.566 \pm 4.1 \%$ \\
\hline \multicolumn{7}{|c|}{ Hard to remove seeds of weeds from the family Asteraceae } \\
\hline $\begin{array}{l}\text { Scented mayweed } \\
\text { (Matricaria chamomilla) }\end{array}$ & 7.77 & $0.273 / 15 \pm 2.9 \%$ & $0.260 / 14 \pm 1.7 \%$ & $0.268 / 5 \pm 2.5 \%$ & $0.395 / 21 \pm 2.2 \%$ & $36.852 \pm 2.7 \%$ \\
\hline
\end{tabular}



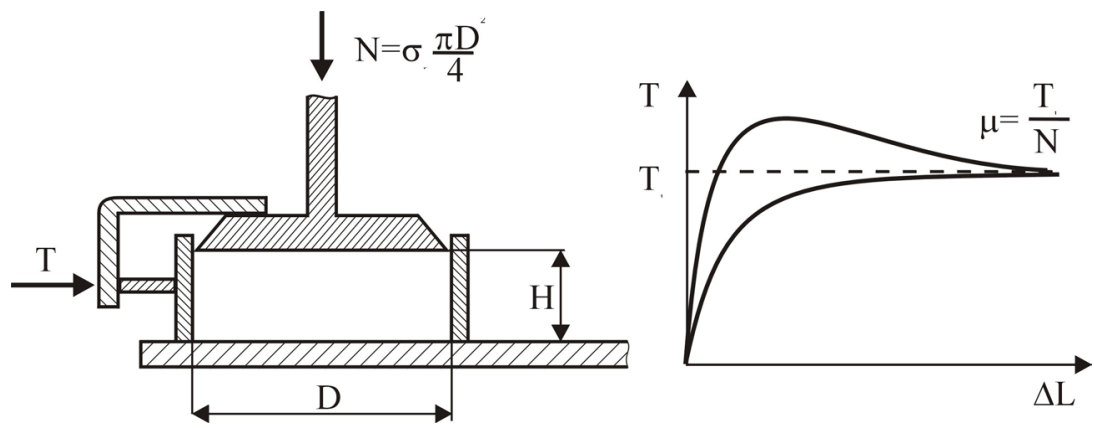

Fig. 1. Schematic diagram of experimental procedure for determination of the wall friction coefficient $(\mu)$ according to Eurocode 1 (2006). N- consolidation stress $(\mathrm{kPa}), \mathrm{T}, \mathrm{T}_{1}$ - shear stress obtained for two different values of consolidation stress $(\mathrm{kPa}), \mathrm{H}-\mathrm{height}$ of the probe in direct shear tester $(\mathrm{mm}), \mathrm{L}$ - displacement of upper ring of tester during measurement $(\mathrm{mm})$.
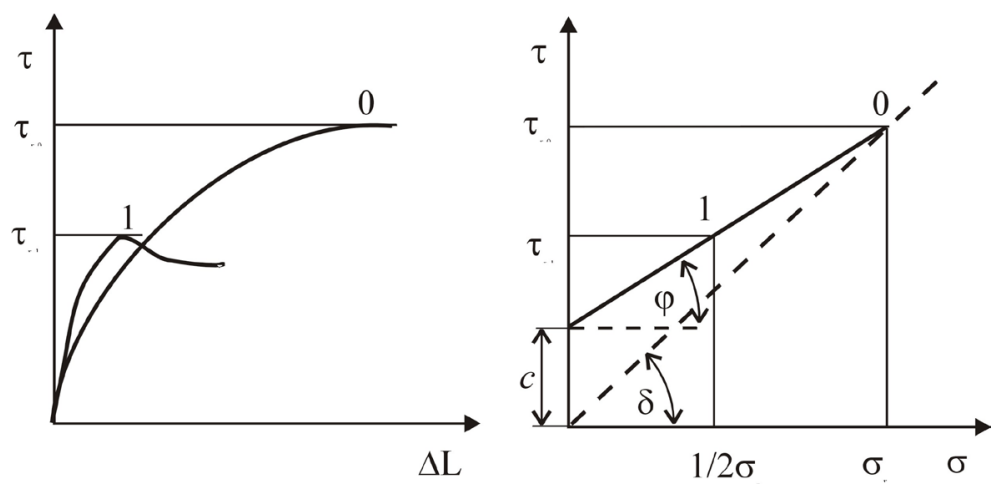

Fig. 2. Determination of shear strength parameters according to Eurocode 1 (2006). $\tau$ - shear stress (kPa), $\tau_{\text {ro }}-$ shear stress obtained for consolidation stress $\sigma_{r}(\mathrm{kPa}), \tau_{\mathrm{r} 1}-$ shear stress obtained for consolidation stress $1 / 2 \sigma_{r}(\mathrm{kPa})$.

For the determination of the value of friction coefficient $\mu$, friction force of a stable value should be applied, occurring at a large displacement $\Delta \mathrm{L}$ (Eurocode 1, 2006).

\section{RESULTS AND DISCUSSION}

The results of variation of the geometric features under study - length, thickness, and width are presented by the cumulative distribution functions, as the example of seeds of the species from the family Poaceae (Figs 3-5).

Figure 6 presents a graph from the recorder of the Jenike apparatus. The vertical axis presents the values of the coefficient of friction $\mu$, and the horizontal axis shows the consecutive measurements in a single test.

Statistical analysis was performed with the use of Microsoft Excel. The values of the coefficient of friction were given in the form of means obtained from the graph. Standard deviation SD $=0.013$, and the coefficient of variance $\mathrm{V}=5.965 \%$. The friction tests were performed in three replications.

The results of the measurements of the coefficient of friction and seed moisture are given in Table 1.

Analysis of the data concerning the friction parameters of the seeds (Table 1) indicates certain differentiation in the values of those parameters among the studied species of pe- rennial plants from the families Fabaceae and Poaceae on all the studied surfaces with the exception of the belted one. The values of the angle of friction of the seeds of English ryegrass and tall meadow oat were 10 and $14^{\circ}$, respectively, those of orchard grass $13-14^{\circ}$, and meadow fescue $13-16^{\circ}$. The variation in the value of this parameter in the case of the belt is greater and forms a range of $30-38^{\circ}$. In the case of smooth brome, the values of the angle on the glass, steel, and aluminium foil surfaces were 9,6 , and $9^{\circ}$, respectively, and on the belt $-23^{\circ}$. However, in the case of occurrence of the main weed - couch grass, the values were a little higher. On the surfaces studied (glass, steel, aluminium foil, and belt), the values of the parameter were $18,17,19$, and $25^{\circ}$, respectively. This allows a conclusion that in the case of separation of seeds from the family of grasses as the main crop, the seeds of couch grass can be separated using glass, steel, or aluminium surfaces. In turn, the use of the belt is not recommended since the differences in the values of those parameters between the seeds are negligible. There are certain possibilities of separating the seeds of timothy grass and scented mayweed, although the differences in the values of the angle of external friction amounting to $3^{\circ}$ indicate a possibility of occurrence of seeds constituting the main crop among the seeds of these weeds. 


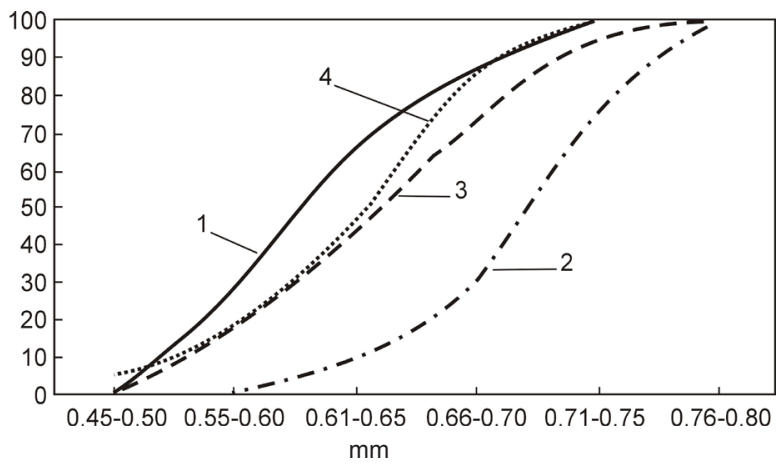

Fig. 3. Examples of distribution functions for seed thickness of plant species from the family Poaceae. 1 - English ryegrass, 2 Couch grass, 3 - Orchard grass, 4 - Meadow fescue.

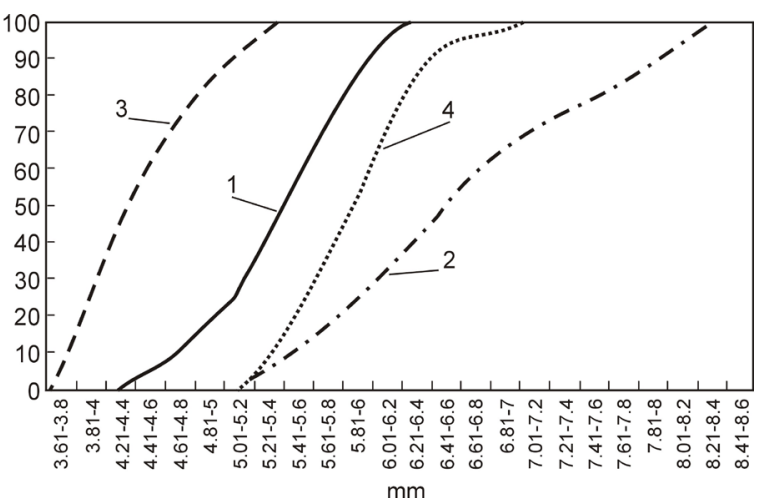

Fig. 5. Distribution functions for seed length of plant species from the family Poaceae. For explanations see Fig. 3.

The angles of internal friction determined for the seeds of perennial grasses and their weeds differ only slightly. The values can be used in fundamental studies related to the design and selection of working elements in separating machines.

Analysis of the data presented in Table 1 allows a conclusion that the values of the measured parameters of the seeds of the family Fabaceae plants: red clover and Swedish clover, and of the seeds of their hard-to-remove admixtures: English ryegrass, sorrel, and white melilot are highly similar to one another. This indicates that for separation thereof the working elements of seed separation machines do not ensure the effects required.

Given the results of research conducted by Kovalyshyn (2013), it can be stated that separation of mixtures of these seeds using some seed separation machines is impossible. At the same time, the study indicates that the geometric parameters do not allow effective separation of seeds of the main crop from seeds of weed admixtures occurring in the input material for the separating machines.

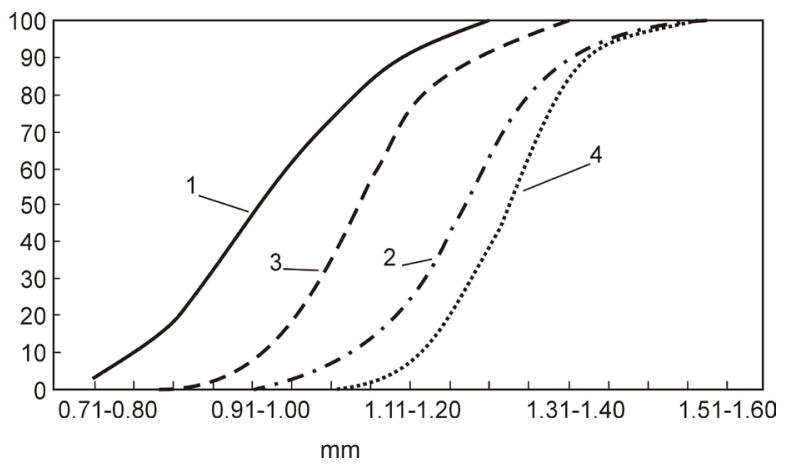

Fig. 4. Distribution functions for seed width of plant species from the family Poaceae. For explanations see Fig. 3.

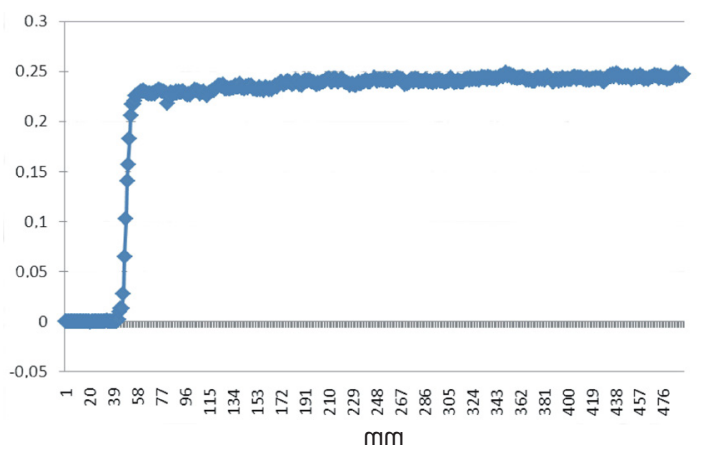

Fig. 6. Values of friction coefficient during experiment.

The difference of substandard seeds and weed impurities can be detected and realized by the complex of their physical, mechanical, and electric properties during electroseparation. Under these conditions, the electric field, which acts as an additional working body, allows considering the surface conditions and biological status of a seed mixture of particles and significantly expands the functionality of the separators. As weeds and crop plants belong to different species, their biological and electric properties differ. Therefore, in an electric field, they will receive different charge and different ways to interact with the working body. Under these conditions, we can expect a positive point of the separation process of hard-to-separate impurities and various low-quality seeds from a mixture of crop seeds. This method of separation can be characterized by the example of separation of red clover from its hard-to-separate its most common weed - sorrel (Rumex confertus) (Asiatic dock). The shape and cross-section of these seeds are shown in Fig. 7. 

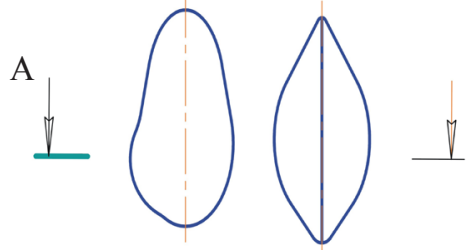

A

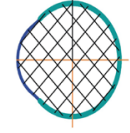

A-A

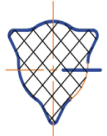

a

b

Fig. 7. Shape and cross-section of separated seeds: a - red clover, b-Asiatic dock.

Fig. 9. Integrated distribution curves of seed equilibrium angle: 1 - moving on an inclined plane, 2 - moving on an inclined plane influenced by electric field.

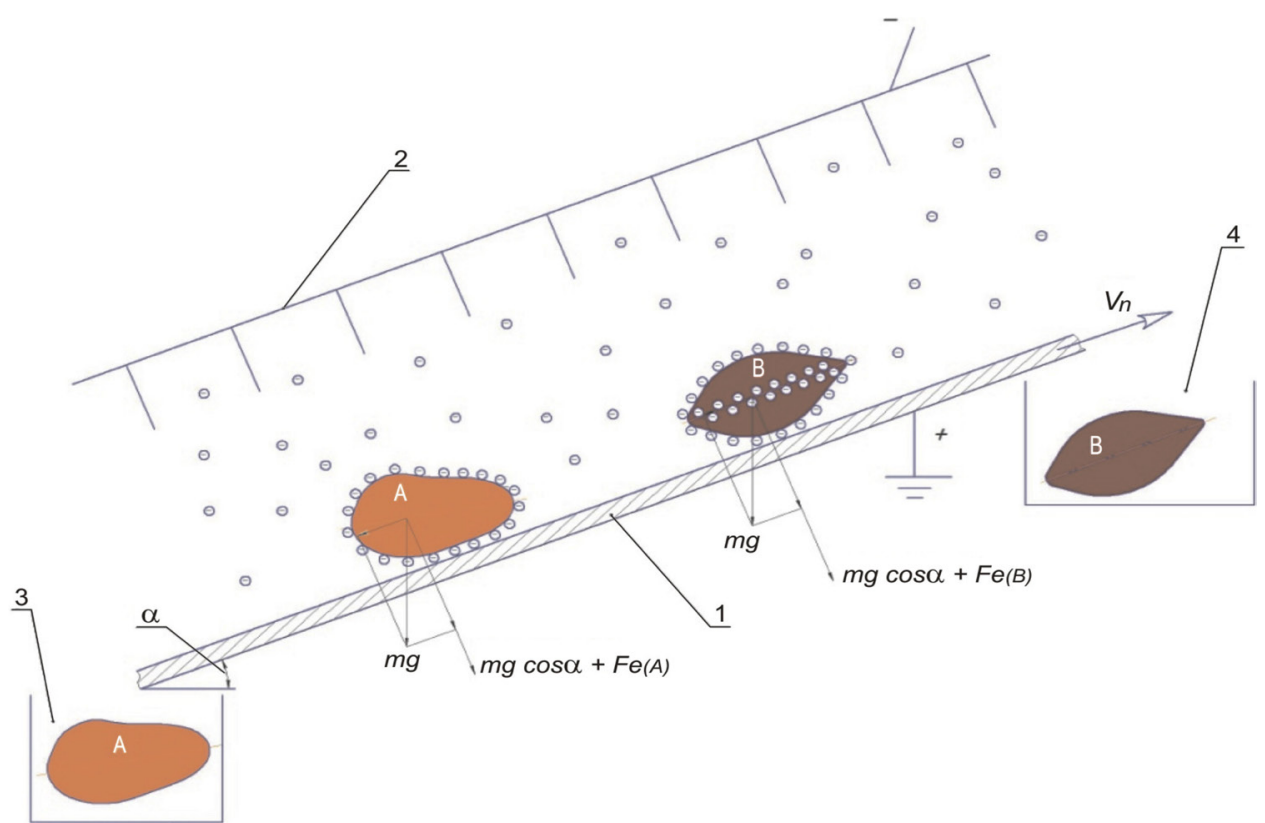

Fig. 8. Principal scheme of electro-separation of hard-to-separate mixture (Kovalyshyn et al., 2013): A - red clover seed, B - Asiatic dock seed, Vn - separation plane motion; 1 - separation plane, 2 - corona separator electrode, 3 - purified seed receiver, 4 - waste receiver.

As noted above, the difference in the geometrical dimensions and friction coefficients of these seeds are very small. The main difference lies is in the surface features of Asiatic dock - the presence of three small ribs. Consider the case of the proposed process of electro-separation where such seeds are in an electric field on an inclined plane friction (Fig. 8).

Decisive in this situation is the electrical properties, such as the charge while they are on the separation plane. Charging is due to sedimentation of negative ions flowing from the needles of corona separator electrode 2 on the surface of seeds.
However, the value of this charge for the mixture components is different. Components that have distinct surface features (Asiatic dock seeds) receive a greater value because ions are concentrated on their edges. They are more pressed by the electric field to the conductive cloth of the separator and together they are moved to the waste receiver 4 . Red clover seeds receive smaller charge because their surface is smoother and without defects, resulting their rolling down the purified seed receiver 3 .

During the separation of seeds on inclined planes due to the complex of their physical, mechanical, and electrical properties, one can always find a slope angle $\alpha$ to horizontal 
plane 1 , by which purified seeds fall into the lower receiver 3 , and weeds and various damaged seeds - into receiver 4, and we achieve the most efficient separation effect.

Confirmation of the effectiveness of the proposed method of separation can be seen in the example of purification of red clover and Asiatic dock seeds by analysing the integral distribution curves of the seed equilibrium angle on an inclined plane (Fig. 9).

Integral curves that characterize the equilibrium angles of seeds on a plane without imposing electric field on it overlap. This is the evidence that the yield of pure clover seeds is $c a$. $30 \%$, and waste reaches $c a .70 \%$, which in turn confirms the ineffectiveness of separation. This is, on the one hand, the evidence that the seeds of red clover and Asiatic dock can be separated without any wastes. On the other hand, these results confirm the effectiveness of the proposed method of separation.

\section{CONCLUSIONS}

1. The study determining the main physical properties of the seeds of perennial grasses and their weeds, namely geometrical parameters, friction coefficients of different friction indicate their essential similarity. On this basis, it can be argued that these features cannot be used as a sign of divisibility in the separation of mixtures of seeds.

2. Improvement of the separation process is possible using the electro-separation method based on the interaction of charge particles from the working bodies of the separator. Under these conditions, the separation occurs on the set of geometrical, mechanical, and electrical properties of the components of seed mixtures.

3. The effectiveness of the proposed method of electro-separation confirms the results, which can be seen in the example of purification of red clover and Asiatic dock seeds. In the process of separation on an inclined plane, removal of pure clover seeds is about $30 \%$, and waste reaches almost $70 \%$. Overlaying this plane by an electric field will ensure separation of the seeds of red clover and Asiatic dock without any wastes.

4. Separation of hard-to-devide seed mixtures of perennial grasses on the set of their physical, mechanical and electrical properties, upon which the proposed method is based, makes a significant interest in terms of improving the existing seed separation machines and their technology use in postharvest handling of seed crops under the studies.

\section{REFERENCES}

Anonymous, 2002. Council Directive 2002/55/EC. European Seed Association. http://www. euroseeds.org
Balasubramianian S., Singh K.K., and Kumar R., 2012. Physical properties of coriander seeds at different moisture content. Int. Agrophys., 26, 419-422.

Ch'ng P.E., Abdullah M.H.R.O., Mathai E.J., and Yunus N.A., 2013. Some physical properties of ginkgo nuts and kernels. Int. Agrophys., 27, 485-489.

Eurocode 1, 2006. Basis of design and action on structure. Actions in silo and tanks. EN 1991-4.

Horabik J. and Molenda M., 1988. Force and contact area of wheat grain in friction. J. Agric. Eng. Res., 41(1), 33-42.

Horabik J. and Molenda M., 1989. Effect of moisture content on friction of wheat grain at single contact area. Powder, Handling Proces., 1(3), 277-279.

Kovalyshyn S.J., 1999. Choice of parameters of perennial grass seed processing on an electro-vibration separator (in Ukrainian). Ph.D. Thesis, Lviv National Agriculture University, Ukraine.

Kovalyshyn S.J., 2013. Research and methodological aspects of preparation of sowing material of species of small-seed plants. Inter-branch collection of topical works (in Ukrainian). Mechanisation Electrification Agriculture Ed., 97(1), 387-393.

Kovalyshyn S.J., Shvets O.P., Grundas S., and Tys J., 2013. Use of the electro-separation method for improvement of the utility value of winter rapeseeds. Int. Agrophys., 27, 491-494.

Molenda M., Horabik J., Grochowicz M., and Szot B., 1995. Friction of wheat grain (in Polish). Acta Agrophysica, 4, $1-88$.

Molenda M., Thompson S.A., and Ross I.J., 2000. Friction of wheat on corrugated and smooth galvanized steel surfaces. J. Agric. Eng. Res., 77(2), 209-219.

Ovsiannikova L.K., Orlova S.S., and Sokolovska O.G., 2009. Comparative analysis of species of small seeds on the basis of their dimensional characteristics (in Ukrainian). Collection Research Works. Odesa National Agro-Technical Academy, 36(1), 121-126.

Ribaruk V.J., 1998. Agricultural machinery. Calculations Practice and Solutions of Operation Processes (in Ukrainian). (Eds V. J. Ribaruk, I.I. Lipka). Lviv National Agriculture University, Ukraine.

Samokish V.V., 2011. Results of a study on the coefficient of external friction of rape seed and seeds of goosegraas (Galium aparine) on various materials (in Ukrainian). Collection Research Works. Podolsk State Agro-Technical Academy, 9, 397-400.

Shevchuk V.V., 2011. Agricultural machinery. Collection of research works (in Ukrainian). Luck National University of Technology, 21(2), 229-234.

Tomiuk V.V., 2008 (Ed.). Determination of angle of external friction of rape seeds (in Ukrainian). News of Lviv National University of Agriculture: Engineering Results, 12(2), 598-602.

Zaika P.M., 2006. Theory of agricultural machines (in Ukrainian). Seed Cleaning Separation, 3, 25-30.

Zare D., Bakshipour A., and Chen G., 2013. Physical properties of cumin and caraway seeds. Int. Agrophys., 27, 491-494. 